\title{
Identification of bacterial pathogens in cultured fish using Matrix-assisted laser desorption/ionization time-of-flight mass spectrometry (MALDI-TOF MS)
}

\section{Patharapol Piamsomboon}

Chulalongkorn University https://orcid.org/0000-0002-6446-6884

Janthima Jaresitthikunchai

National Center for Genetic Engineering and Biotechnology

Tran Quang Hung

Jihoceska Univerzita v Ceskych Budejovicich

Sittiruk Roytrakul

National Center for Genetic Engineering and Biotechnology

Janenuj Wongtavatchai ( $\nabla$ janenuj.w@chula.ac.th )

Research article

Keywords: Mass spectrometry, Proteomic, Fish disease, Biotyper

Posted Date: October 8th, 2019

DOI: https://doi.org/10.21203/rs.2.15702/v1

License: (c) (i) This work is licensed under a Creative Commons Attribution 4.0 International License.

Read Full License 


\section{Abstract}

Background Majority of infectious diseases of cultured fish is caused by bacteria. Rapid identification of bacterial pathogen is necessary for immediate management. The present study developed Matrixassisted laser desorption/ionization time-of-flight mass spectrometry (MALDI-TOF MS) for a fast identification of fish bacterial pathogens. Streptococcus agalactiae, S. iniae, Aeromonas hydrophila, A. veronii, and Edwardsiella tarda obtained from diseased fish were used as representative bacterial pathogens in this study. Bacterial peptides were extracted to create the Main Spectra Profile (MSP), and the MSP of each bacterial species was added into the MALDI Biotyper database. Ten additional field isolates of each bacterial species were tested to validate the technique.Results The MSP of all field isolates were clearly distinguishable, and the MSPs of the same species were clustered together. However, the species identification when matching with the public MALDI Biotyper library (Bruker MALDI Biotyper) showed unreliable result at the species level. The accurate identification only obtained when the custommade database was used, giving a 100\% matching result.Conclusion This study demonstrates a newly developed technique for the effective identification of fish bacterial pathogens. Further applications require a broad, well-established database to accommodate the prudent identification of many fish bacterial pathogens by MALDI-TOF MS.

\section{Background}

Bacterial pathogens are a major etiology of infectious diseases ofcultured fish [1]. Among those bacteria, Streptococcus spp., Aeromonas spp., and Edwardsiella spp.,, are commonly found in several important aquaculture species, such as the Asian catfish Clarias batrachus [2], barramundi Lates calcarifer [3], and Nile tilapia Oreochromis niloticus 4]. In many cases of bacterial infection, clinical signs and lesions are not specific and may mislead the diagnosis. Therefore, identification of bacterial species causing disease is necessary in order to carry out proper disease management.

Conventional microbiology, including morphological, physiological and biochemical tests, and molecular techniques based on 16S rDNA sequencing, are the gold standard for bacterial species identification [5]. However, these techniques require a substantial amount of time and expensive reagents [6]. The recent development of mass spectrometry (MS), the Matrix-assisted laser desorption/ionization time-of-flight mass spectrometry (MALDI-TOF MS) has been implemented in human and veterinary medicine as an alternative diagnostic tool with increasing popularity due to its quickness, simplicity, cost-effectiveness, and strong discriminating power $[7,8]$. The MALDI-TOF MS detects the mass signals from bacterial proteins or peptides and determines their unique mass spectra or peptide mass fingerprints (PMFs). The obtained PMFs are then compared with reference bacterial strains in the public proteomics/genomics databases or in a dedicated mass spectra library (library based approach) [9], which is able to differentiate the bacteria at their genus, species or sub-group levels subject to sufficient reference strains existing in the database [10]. 
The MALDI-TOF MS approach has been adopted as a routine diagnostic tool for human medicine [11] and also has been widely evaluated for the ability to differentiate bacterial species of veterinary and public health importance. For example, S. equi at subspecies level [8], Streptococcus spp. isolated from diseased pigs [12], pathogenic Gram-negative bacteria in seafood [13] and Aeromonad species found in a drinking water system [14] have been assessed. In fish, MALDI-TOF was evaluated for the fast identification of Gram-positive bacterial pathogens, including S. agalactiae, Lactococcus garvieae, $S$. iniae, and S. dysgalactiae isolated from Nile tilapia [15] and S. iniae isolated from the olive flounder Paralichthys olivaceus [16]. These studies found that the public database, Bruker MALDI Biotyper library, was insufficient for identifying bacterial species isolated from fish with MALDI-TOF.

Therefore, the present study aims to develop a custom Main Spectra Profile (MSP) database and validate the method using MALDI-TOF MS for a rapid and accurate identification of S. agalactiae, S. iniae, A. hydrophila, A. veronii and $E$. tarda isolated from economically important fish species.

\section{Results}

\section{MALDI-TOF MS for bacterial species differentiation}

The high reliability of the MALDI-TOF MS was indicated by the obtained $100 \%$ recognition capabilities and by the cross-validation values of $87.8 \%, 97.1 \%, 100 \%, 100 \%$, and $100 \%$ for S. agalactiae, S. iniae. A. hydrophila, $A$. veronii, and $E$. tarda, respectively. The five bacterial species showed distinguishing spectral peaks ranging between 2,000-15,000 Da (Fig. 1). The 3D-PCA scatterplot and the MSP dendrogram presented clearly distinguishable clusters for each bacterial species. For the MSP dendrogram, bacterial isolates within the same species were grouped in the same clade and the same genus were placed closer to each other (Fig. 2A and 2B).

\section{MALDI Biotyper database}

The additional field isolates, when blasted against the reference strains available in the Bruker database, gave no-reliable identification for 12 isolates (log score 1.454-1.667), probable genus-level identification for 31 isolates (log score 1.707-1.997), and secure genus-level identification for seven isolates (log score 2.018-2.254). No species-level identification was obtained, especially for $S$. iniae since it is not available in the Bruker database.

A custom database of the five bacterial fish pathogens was then established. Matching results of the field strain were improved, showing nine isolates with a secure genus-level identification to a probable species-level identification (log score 2.115-2.264) and 41 isolates with a highly probable species-level identification (log score 2.301-2.601) (Table 2). Specificity of the method was indicated by the $100 \%$ species identification compared with the $16 \mathrm{~S}$ rDNA sequencing, and no mis-identification at species level was observed. 


\section{Discussion}

An accurate and repeatable method for the identification of bacterial pathogens of aquaculture species was developed in this study. It can be performed in a relatively short time with a lower cost compared to conventional biochemical methods. However, the correct identification of bacterial species was only obtained when a custom database was constructed because the reference database does not accommodate the tested pathogens. The reference database may only contain bacterial species that are significant to humans but not species of veterinary importance, particularly from aquatic species [21]. The failure in species identification from the Bruker database may also result from inconsistent protein profiles due to the use of different sample preparation protocols. The extraction method usually involves the use of organic acid to extract small-sized protein molecules, such as ribosomal proteins, cold shock proteins, and nucleic-acid binding proteins [22]. The different percentage of acid used in other studies $[50 \%$ ACN and $2.5 \%$ TFA] $[16,23,24]$ may alter the pattern of those extracted proteins. Nevertheless, ability to tailor a database expands the application of MALDI Biotyper to be used as an identification tool for bacterial species specific to a host or location, and at below species-level, such as sub-species, strain, or serotype $[25,26]$.

Besides the identification purpose of MALDI-TOF, the 3D-PCA scatterplot generated from the protein profile can be used for grouping and differentiation of the protein profile of the organism. The protein profile analyzed with MALDI-TOF MS in the present study clearly showed separate clusters of each bacterial species on the 3D-PCA scatterplot and MSP dendrogram, indicating the discriminating power of the method. The MALDI-TOF MS approach has also been used to distinguish antimicrobial resistant Enterobacteriaceae [27], differentiate Burkholderia pseudomallei mutants [22], and even in screening for early or late stage cancer [28]. Therefore, MALDI-TOF MS can be a useful tool for investigating aquatic pathogens in many aspects.

In the present study, we provide an example of a MSP dendrogram created by the Biotyper software, by grouping the bacteria based on their phenotypic traits instead of their genetic traits. Interestingly, the ATCC strains from the reference database showed a high distance level to the field strains, and this may explain the failure of species identification described previously. Genotyping is usually based on phylogenetic analysis of a highly conserved region of the ribosomal RNA of the bacteria and this conservative feature may limit classification of the bacteria. Several studies have used MALDI-TOF MS as a discriminatory tool for typing bacterial pathogens $[21,29,30]$, and found that genotypic and phenotypic traits do not always concur [31]. However, MALDI-TOF MS can be used as an additional method for bacterial taxonomic classification, which may benefit further research, such as epidemiology, identification of protein biomarkers, and virulence studies.

\section{Conclusions}

To our knowledge, the present study is the first to describe a MSP database for both Gram-positive (Streptococcus) and Gram-negative (Aeromonas and Edwardsiella) bacterial pathogens of cultured fish. It 
could establish species-level identifications, even when the source of those bacteria was from different geographical locations or host species. However, this specificity can be obtained only when the custom MALDI Biotyper database was constructed with a standard sample preparation protocol. For the most reliable result, we suggested that the database of each user should contain a custom MSP of the active local pathogenic strains.

\section{Methods}

\section{Bacterial samples}

All bacterial isolates were obtained from clinical cases that were submitted to the Faculty of Veterinary Science, Chulalongkorn University for disease diagnosis. Bacterial isolation was performed on kidney tissues using Columbia blood agar supplemented with $5 \%$ sheep blood (Oxiod, Basingstoke, UK) and incubated at $28{ }^{\circ} \mathrm{C}$ for $24 \mathrm{~h}$. Bacterial species were identified by conventional microbiology methods, including Gram staining, catalase and oxidase production tests, and API identification (BioMérieus ${ }^{\circledR}$, France). Bacterial species were confirmed using PCR amplification and sequencing of the 16S rDNA [17]. Pure bacterial isolates were stored in nutrient broth (NB; Oxiod) containing $10 \%$ fetal calf serum and $20 \%$ glycerol at $-80^{\circ} \mathrm{C}$ for further analysis.

\section{Sample preparation for MALDI-TOF MS}

Each bacterial isolate was revived from the stock onto Columbia blood agar and incubated at $28{ }^{\circ} \mathrm{C}$ for $18 \mathrm{~h}$. Extraction of bacterial proteins was performed as previously described by [18]. Briefly, a loopfull of bacterial colonies was suspended in $70 \%$ ethanol and the suspension was centrifuged at $11,000 \mathrm{~g}$ for 2 min. The supernatant was removed, and the bacterial pellet was resuspended and mixed thoroughly with $100 \%$ acetonitrile (ACN) containing $5 \%(\mathrm{w} / \mathrm{v})$ trifluoroacetic acid (TFA). The suspension was centrifuged and the supernatant was collected for peptide measurement using Lowry's assay at $690 \mathrm{~nm}$ absorbance [19]. The concentration of peptide was adjusted to $0.1 \mu \mathrm{g} \mathrm{L}^{-1}$ for the MALDI-TOF MS analysis.

\section{MALDI-TOF MS for database generation}

Five bacterial isolates of each bacterial species were used as a representative for the MSP database preparation (Table 1). Peptide patterns of all isolates were identified by MALDI-TOF MS togenerate a database specific to each bacterial species. The MALDI matrix solution $\left[10 \mathrm{mg} \mathrm{mL}^{-1}\right.$ sinapinic acid in $100 \%$ ACN containing $5 \%(\mathrm{w} / \mathrm{v})$ TFA] was added to each sample $\left(0.1 \mu \mathrm{g} \mu \mathrm{L}^{-1}\right.$ peptide) at a $1: 1(\mathrm{v} / \mathrm{v})$ ratio. The mixed samples were spotted and air dried onto a MTP 384 ground steel target plate (Bruker Daltonics, Billerica, MA) as 29 individual replicates. Mass spectra were obtained using an Ultraflex III TOF/TOF (Bruker Daltonik, $\mathrm{GmbH}$ ) in a linear positive mode with a mass range between 2-20 kDa and a laser frequency of $50 \mathrm{~Hz}$ and 500 laser shots. 
Fingerprint spectra were calibrated and analyzed by the flexAnalysis software version 3.4. The reliability of the results was analyzed by t-test/ANOVA and a construction of three-dimensional principal component analysis (3D-PCA) scatterplot was performed using ClinProTools software version 3.0. Database construction was performed according to Bruker's recommendation, where a total of 20 apparent peptide spectra of each isolate were selected to be uploaded into MALDI Biotyper (version 4.0). The MSP dendrogram of the MALDI-TOF MS derived data was then created from the constructed database in order to evaluate the relatedness of each bacterial species based on their peptide spectra.

\section{Method validation and bacterial species identification}

The same bacterial isolate was processed twice using a similar protocol and analyzed by MAILDI-TOF MS to evaluate the repeatability of the method. To assess the specificity of the method, additional field isolates of the five pathogens (10 additional isolates/pathogen) were used. All isolates were identified using 16S rDNA PCR and sequencing, as previously described [17], and were then identified by the MALDITOF MS method. The samples were spotted as eight individual replicates on the MALDI plate, blasted with both the Bruker database and then the created database. The reliability of the method was determined based on log score values; $<1.700=$ no reliable identification, $\geq 1.700-1.999=$ probable genus-level identification, $2.000-2.229$ = a secure genus-level identification and a probable species-level identification, and 2.300-3.000 = a highly probable species-level identification [20].

\section{Declarations}

\section{Acknowledgments}

Not applicable.

\section{Authors' contributions}

PP and JW participated to the study design and planning. PP, SR and JW organized the project and agreed the objectives of the study. PP and TQH executed the sample collection. PP and JJ performed the sample treatment, method validation, and instrumental analysis. PP and JW prepared initial draft of the manuscript. SR and JW made revision and refinement of the manuscript. SN and JW applied for project's funding. All Authors read and approved the final manuscript.

\section{Funding}

This study was supported by Grants for Development of New Faculty Staff, Ratchadaphiseksomphot Endowment Fund, Chulalongkorn University.

\section{Availability of data and materials}


The datasets used and analyzed during the study are available from the corresponding author upon request.

\section{Ethics approval and consent to participate}

Not applicable.

\section{Consent for publication}

Not applicable.

\section{Competing interests}

The authors declare that they have no competing interests.

\section{Author details}

${ }^{1}$ Department of Veterinary Medicine, Faculty of Veterinary Sciences, Chulalongkorn University, Bangkok, Thailand. ${ }^{2}$ Proteomics Research Laboratory, National Center for Genetic Engineering and Biotechnology, Pathum Thani, Thailand. ${ }^{3}$ Laboratory of Controlled Reproduction and Intensive Fish Culture, Faculty of Fisheries and Protection of Waters, University of South Bohemia in České Budějovice, eské Budějovice, Czech Republic

\section{References}

1.Lafferty KD, Harvell CD, Conrad JM, Friedman CS, Kent ML, Kuris AM, Powell EN, Rondeau D, Saksida SM: Infectious diseases affect marine fisheries and aquaculture economics. Annu Rev Mar Sci.2015, 7:471-496.

2.Sahoo P, Mukherjee S, Sahoo S: Aeromonas hydrophila versus Edwardsiella tarda: a pathoanatomical study in Clarias batrachus. J Aquacult.1998, 6:57-66.

3.Bromage ES, Owens L: Infection of barramundi Lates calcarifer with Streptococcus iniae: effects of different routes of exposure. Dis Aquat Organ.2002, 52(3):199-205.

4.Jantrakajorn S, Maisak H, Wongtavatchai J: Comprehensive investigation of streptococcosis outbreaks in cultured Nile tilapia, Oreochromis niloticus, and red tilapia, Oreochromis sp., of Thailand. J World Aquacult Soc.2014, 45(4):392-402.

5.Laupland KB, Valiquette L: The changing culture of the microbiology laboratory. Can $\mathrm{J}$ Infect Dis Med Microbiol.2013, 24(3):125-128. 
6.Buller NB: Bacteria from fish and other aquatic animals: a practical identification manual. UK: Cabi Publishing; 2004.

7.Angeletti S: Matrix assisted laser desorption time of flight mass spectrometry (MALDI-TOF MS) in clinical microbiology. J Microbiol Methods.2017, 138:20-29.

8.Kudirkiene E, Welker M, Knudsen NR, Bojesen AM: Rapid and accurate identification of Streptococcus equi subspecies by MALDI-TOF MS. Syst Appl Microbiol.2015, 38(5):315-322.

9.Popović NT, Kazazić SP, Strunjak-Perović I, Čož-Rakovac R: Differentiation of environmental aquatic bacterial isolates by MALDI-TOF MS. Environ Res.2017, 152:7-16.

10.Benagli C, Demarta A, Caminada A, Ziegler D, Petrini O, Tonolla M: A rapid MALDI-TOF MS identification database at genospecies level for clinical and environmental Aeromonas strains. PLoS One.2012, 7(10):e48441.

11.Faron ML, Buchan BW, Hyke J, Madisen N, Lillie JL, Granato PA, Wilson DA, Procop GW, NovakWeekley S, Marlowe E: Multicenter evaluation of the Bruker MALDI Biotyper CA system for the identification of clinical aerobic gram-negative bacterial isolates. PloS one.2015, 10(11):e0141350.

12.Pérez-Sancho M, Vela Al, García-Seco T, González S, Domínguez L, Fernández-Garayzábal JF: Usefulness of MALDI-TOF MS as a diagnostic tool for the identification of Streptococcus species recovered from clinical specimens of pigs. PloS one.2017, 12(1):e0170784.

13.Böhme K, Fernández-No IC, Barros-Velázquez J, Gallardo JM, Calo-Mata P, Canas B: Species differentiation of seafood spoilage and pathogenic gram-negative bacteria by MALDI-TOF mass fingerprinting. J Proteome Res.2010, 9(6):3169-3183.

14.Donohue MJ, Best JM, Smallwood AW, Kostich M, Rodgers M, Shoemaker JA: Differentiation of Aeromonas isolated from drinking water distribution systems using matrix-assisted laser desorption/ionization-mass spectrometry. Anal Chem.2007, 79(5):1939-1946.

15.Assis GB, Pereira FL, Zegarra AU, Tavares GC, Leal CA, Figueiredo HC: Use of MALDI-TOF mass spectrometry for the fast identification of gram-positive fish pathogens. Front Microbiol.2017, 8:1492.

16.Kim SW, Nho SW, Im SP, Lee JS, Jung JW, Lazarte JMS, Kim J, Lee W-J, Lee J-H, Jung TS: Rapid MALDI biotyper-based identification and cluster analysis of Streptococcus iniae. J Microbiol.2017, 55(4):260-266.

17.Weisburg WG, Barns SM, Pelletier DA, Lane DJ: 16S ribosomal DNA amplification for phylogenetic study. J Bacteriol.1991, 173(2):697-703.

18.Jaresitthikunchai J., Phanphiriya P., S. R: MALDI-TOF Mass Spectrometric Fingerprint for Direct Identification of Bacillus, Escherichia, Staphylococcus, Enterobacter, Pseudomonas from Colonies Grown 
on Agar Plates In: Proceeding of The 3rd International Conference on Biochemistry and Molecular Biology $2011 ; 2011$.

19.Lowry OH, Rosebrough NJ, Farr AL, Randall RJ: Protein measurement with the Folin phenol reagent. J Biol Chem.1951, 193:265-275.

20.Cherkaoui A, Hibbs J, Emonet S, Tangomo M, Girard M, Francois P, Schrenzel J: Comparison of two matrix-assisted laser desorption ionization-time of flight mass spectrometry methods with conventional phenotypic identification for routine identification of bacteria to the species level. J Clin Microbiol.2010, 48(4):1169-1175.

21.Kim SW, Jang HB, Lee JS, Im SP, Lazarte JMS, Seo JP, Lee WJ, Kim JS, Jung TS: Comparison of proteome typing and serotyping of Streptococcus parauberis isolates from olive flounder (Paralichthys olivaceus).. J Microbiol Methods.2015, 118:168-172.

22.Niyompanich S, Srisanga K, Jaresitthikunchai J, Roytrakul S, Tungpradabkul S: Utilization of wholecell MALDI-TOF mass spectrometry to differentiate Burkholderia pseudomallei wild-type and constructed mutants. PloS one.2015, 10(12):e0144128.

23.Alatoom AA, Cunningham SA, Ihde SM, Mandrekar J, Patel R: Comparison of direct colony method versus extraction method for identification of Gram-positive cocci by use of Bruker Biotyper matrixassisted laser desorption ionization-time of flight mass spectrometry. J Clin Microbiol.2011, 49(8):2868-2873.

24.Matsuda N, Matsuda M, Notake S, Yokokawa H, Kawamura Y, Hiramatsu K, Kikuchi K: Evaluation of a simple protein extraction method for species identification of clinically relevant staphylococci by matrixassisted laser desorption ionization-time of flight mass spectrometry. J Clin Microbiol.2012, 50(12):3862-3866.

25.Mclean K, Palarea-Albaladejo J, Currie CG, Imrie LH, Manson ED, Fraser-Pitt D, Wright F, Alexander CJ, Pollock KG, Allison L: Rapid and robust analytical protocol for E. coli STEC bacteria subspecies differentiation using whole cell MALDI mass spectrometry. Talanta.2018, 182:164-170.

26.Rothen J, Pothier JF, Foucault F, Blom J, Nanayakkara D, Li C, Ip M, Tanner M, Vogel G, Pflüger V: Subspecies typing of Streptococcus agalactiae based on ribosomal subunit protein mass variation by MALDI-TOF MS. Front Microbiol.2019, 10:471.

27.Arpornsuwan T, Paveenkittiporn W, Jaresitthikunchai J, Roytrakul S: BAMP-28 Antimicrobial Peptide Against Different MALDI Biotype of Carbapenam Resistant Enterobacteriaceae. International Journal of Peptide Research and Therapeutics.2018:1-10.

28.Ploypetch S, Roytrakul S, Jaresitthikunchai J, Phaonakrop N, Krobthong S, Suriyaphol G: Salivary proteomics of canine oral tumors using MALDI-TOF mass spectrometry and LC-tandem mass 
spectrometry. PloS one.2019, 14(7):e0219390.

29.Carannante A, De Carolis E, Vacca P, Vella A, Vocale C, De Francesco MA, Cusini M, Del Re S, Dal Conte I, Cristaudo A: Evaluation of matrix-assisted laser desorption ionization-time of flight mass spectrometry (MALDI-TOF MS) for identification and clustering of Neisseria gonorrhoeae. BMC microbiology.2015, 15(1):142.

30.Batah R, Loucif L, Olaitan AO, Boutefnouchet N, Allag H, Rolain J-M: Outbreak of Serratia marcescens coproducing ArmA and CTX-M-15 mediated high levels of resistance to aminoglycoside and extendedspectrum beta-lactamases, Algeria. Microbial Drug Resistance.2015, 21(4):470-476.

31.Rim JH, Lee Y, Hong SK, Park Y, Kim M, D’Souza R, Park ES, Yong D, Lee K: Insufficient discriminatory power of matrix-assisted laser desorption ionization time-of-flight mass spectrometry dendrograms to determine the clonality of multi-drug-resistant Acinetobacter baumannii isolates from an intensive care unit. Biomed Res Int.2015, 2015:535027.

\section{Tables}

Table 1 Bacterial pathogens used for the development the MSP database. The isolates were obtained from cultured Nile tilapia Oreochromis niloticus, red tilapia Oreochromis spp., barramundi Lates calcarifer, hybrid catfish Clarias macrocephalus $x$ C. gariepinus, and Snakehead fish Channa striata. 


\begin{tabular}{|c|c|c|c|c|}
\hline Bacterial species & Isolate number & Year & Source & Region \\
\hline \multirow[t]{5}{*}{ S. agalactiae } & S147-J & 2013 & Nile tilapia & Western Thailand \\
\hline & S183-J & 2015 & Red tilapia & Central Thailand \\
\hline & S187-J & 2017 & Nile tilapia & Eastern Thailand \\
\hline & S190-J & 2018 & Red tilapia & Southern Thailand \\
\hline & SV1/1-J & 2018 & Nile tilapia & Northern Vietnam \\
\hline \multirow[t]{5}{*}{ S. iniae } & NS12-J & 2007 & Red tilapia & Northeastern Thailand \\
\hline & NS70-J & 2012 & Nile tilapia & Northeastern Thailand \\
\hline & NS74-J & 2014 & Barramundi & Eastern Thailand \\
\hline & NS76-J & 2014 & Barramundi & Eastern Thailand \\
\hline & NS185-J & 2018 & Barramundi & Eastern Thailand \\
\hline \multirow[t]{5}{*}{ A. hydrophila } & A28-J & 2011 & Nile tilapia & Eastern Thailand \\
\hline & A29-J & 2011 & Hybrid catfish & Eastern Thailand \\
\hline & A49-J & 2013 & Red tilapia & Central Thailand \\
\hline & A50-J & 2015 & Nile tilapia & Eastern Thailand \\
\hline & A84-J & 2017 & Snakehead fish & Central Thailand \\
\hline \multirow[t]{5}{*}{ A. veronii } & SB1-J & 2017 & Nile tilapia & Eastern Thailand \\
\hline & SB2-J & 2017 & Nile tilapia & Eastern Thailand \\
\hline & SB3-J & 2018 & Barramundi & Eastern Thailand \\
\hline & SB4-J & 2019 & Barramundi & Eastern Thailand \\
\hline & SB7-J & 2019 & Red tilapia & Eastern Thailand \\
\hline \multirow[t]{5}{*}{ E. tarda } & Ed10-J & 2012 & Hybrid catfish & Central Thailand \\
\hline & Ed12-J & 2013 & Hybrid catfish & Central Thailand \\
\hline & Ed14-J & 2015 & Nile tilapia & Eastern Thailand \\
\hline & Ed16-J & 2016 & Nile tilapia & Eastern Thailand \\
\hline & Ed18-J & 2017 & Nile tilapia & Central Thailand \\
\hline
\end{tabular}

Table 2 Method validation of the MALDI Biotyper using field strains of five bacterial pathogens showing the matching results with the custom MSP and the Bruker MSP database. 


\begin{tabular}{|c|c|c|c|c|c|}
\hline \multirow[t]{2}{*}{ Isolate number } & \multirow[t]{2}{*}{ Source } & \multicolumn{2}{|c|}{ Custom MSP database } & \multicolumn{2}{|c|}{ Bruker MSP database } \\
\hline & & Organism best match & Log score & Organism best match & Log score \\
\hline \multicolumn{6}{|c|}{ Streptococcus spp. } \\
\hline S71 & Red tilapia & S. agalactiae & 2.244 & S. urinalis & 1.666 \\
\hline S96 & Red tilapia & S. agalactiae & 2.377 & S. agalactiae & 1.756 \\
\hline S100 & Nile tilapia & S. agalactiae & 2.442 & S. agalactiae & 1.582 \\
\hline S101 & Nile tilapia & S. agalactiae & 2.375 & S. parauberis & 1.829 \\
\hline S102 & Nile tilapia & S. agalactiae & 2.544 & S. parauberis & 1.876 \\
\hline S183 & Red tilapia & S. agalactiae & 2.388 & S. agalactiae & 1.716 \\
\hline S184 & Red tilapia & S. agalactiae & 2.591 & S. agalactiae & 1.749 \\
\hline S191 & Red tilapia & S. agalactiae & 2.347 & S. urinalis & 1.564 \\
\hline S195 & Nile tilapia & S. agalactiae & 2.455 & S. agalactiae & 1.632 \\
\hline S198 & Nile tilapia & S. agalactiae & 2.544 & S. agalactiae & 1.908 \\
\hline NS11 & Nile tilapia & S. iniae & 2.376 & S. agalactiae & 1.997 \\
\hline NS18 & Nile tilapia & S. iniae & 2.419 & S. agalactiae & 1.707 \\
\hline NS26 & Red tilapia & S. iniae & 2.534 & S. pyogenes & 1.728 \\
\hline NS34 & Barramundi & S. iniae & 2.544 & S. agalactiae & 1.886 \\
\hline NS50 & Barramundi & S. iniae & 2.308 & S. pyogenes & 1.679 \\
\hline NS84 & Barramundi & S. iniae & 2.118 & S. pyogenes & 1.679 \\
\hline NS85 & Barramundi & S. iniae & 2.445 & S. agalactiae & 1.864 \\
\hline NS89 & Red tilapia & S. iniae & 2.342 & S. agalactiae & 1.975 \\
\hline NS90 & Red tilapia & S. iniae & 2.221 & S. agalactiae & 1.873 \\
\hline NS91 & Nile tilapia & S. iniae & 2.464 & S. parauberis & 1.593 \\
\hline \multicolumn{6}{|l|}{ Aeromonas spp. } \\
\hline A90 & Nile tilapia & A. hydrophila & 2.312 & A. veronii & 2.018 \\
\hline A108 & Hybrid catfish & A. hydrophila & 2.464 & A. hydrophila & 1.956 \\
\hline A109 & Red tilapia & A. hydrophila & 2.115 & A. hydrophila & 1.848 \\
\hline A110 & Snakehead fish & A. hydrophila & 2.394 & A. hydrophila & 2.181 \\
\hline $\mathrm{A} 112$ & Snakehead fish & A. hydrophila & 2.601 & A. hydrophila & 2.011 \\
\hline A114 & Nile tilapia & A. hydrophila & 2.451 & A. veronii & 1.995 \\
\hline A115 & Nile tilapia & A. hydrophila & 2.551 & A. ichthiosmia & 2.045 \\
\hline A120 & Hybrid catfish & A. hydrophila & 2.009 & A. veronii & 1.454 \\
\hline A126 & Snakehead fish & A. hydrophila & 2.567 & A. veronii & 1.777 \\
\hline $\mathrm{A} 127$ & Snakehead fish & A. hydrophila & 2.301 & A. shigelloides & 1.985 \\
\hline SB5 & Nile tilapia & A. veronii & 2.327 & A. ichthiosmia & 2.027 \\
\hline SB6 & Nile tilapia & A. veronii & 2.454 & A. hydrophila & 1.787 \\
\hline SB8 & Barramundi & A. veronii & 2.382 & A. hydrophila & 1.844 \\
\hline SB9 & Barramundi & A. veronii & 2.511 & A. veronii & 1.906 \\
\hline SB10 & Barramundi & A. veronii & 2.377 & A. veronii & 1.733 \\
\hline SB12 & Barramundi & A. veronii & 2.401 & A. veronii & 1.667 \\
\hline SB13 & Barramundi & A. veronii & 2.359 & A. hydrophila & 1.872 \\
\hline
\end{tabular}




\begin{tabular}{llllll}
\hline Isolate number & Source & \multicolumn{2}{c}{ Custom MSP database } & \multicolumn{2}{c}{ Bruker MSP database } \\
\cline { 3 - 5 } & & Organism best match & Log score & Organism best match & Log score \\
\hline SB14 & Barramundi & A. veronii & 2.228 & A. ichthiosmia & 1.560 \\
\hline SB15 & Barramundi & A. veronii & 2.553 & A. veronii & 1.924 \\
\hline SB17 & Barramundi & A. veronii & 2.198 & A. veronii & 1.855 \\
\hline Edwardsiella tarda & & & & \\
Ed8 & Hybrid catfish & E. tarda & 2.382 & E. hoshinae & 1.584 \\
\hline Ed9 & Hybrid catfish & E. tarda & 2.367 & E. hoshinae & 1.624 \\
\hline Ed11 & Hybrid catfish & E. tarda & 2.203 & E. hoshinae & 1.782 \\
\hline Ed17 & Nile tilapia & E. tarda & 2.471 & E. tarda & 1.977 \\
\hline Ed20 & Nile tilapia & E. tarda & 2.457 & E. tarda & 1.945 \\
\hline Ed23 & Hybrid catfish & E. tarda & 2.457 & E. tarda & 2.254 \\
\hline Ed25 & Hybrid catfish & E. tarda & 2.342 & E. tarda & 1.963 \\
\hline Ed27 & Nile tilapia & E. tarda & 2.264 & E. tarda & 2.014 \\
\hline Ed30 & Nile tilapia & E. tarda & 2.445 & E. tarda & 2.002 \\
\hline Ed31 & Nile tilapia & E. tarda & 2.116 & E. tarda & 1.956 \\
\hline
\end{tabular}

\section{Figures}



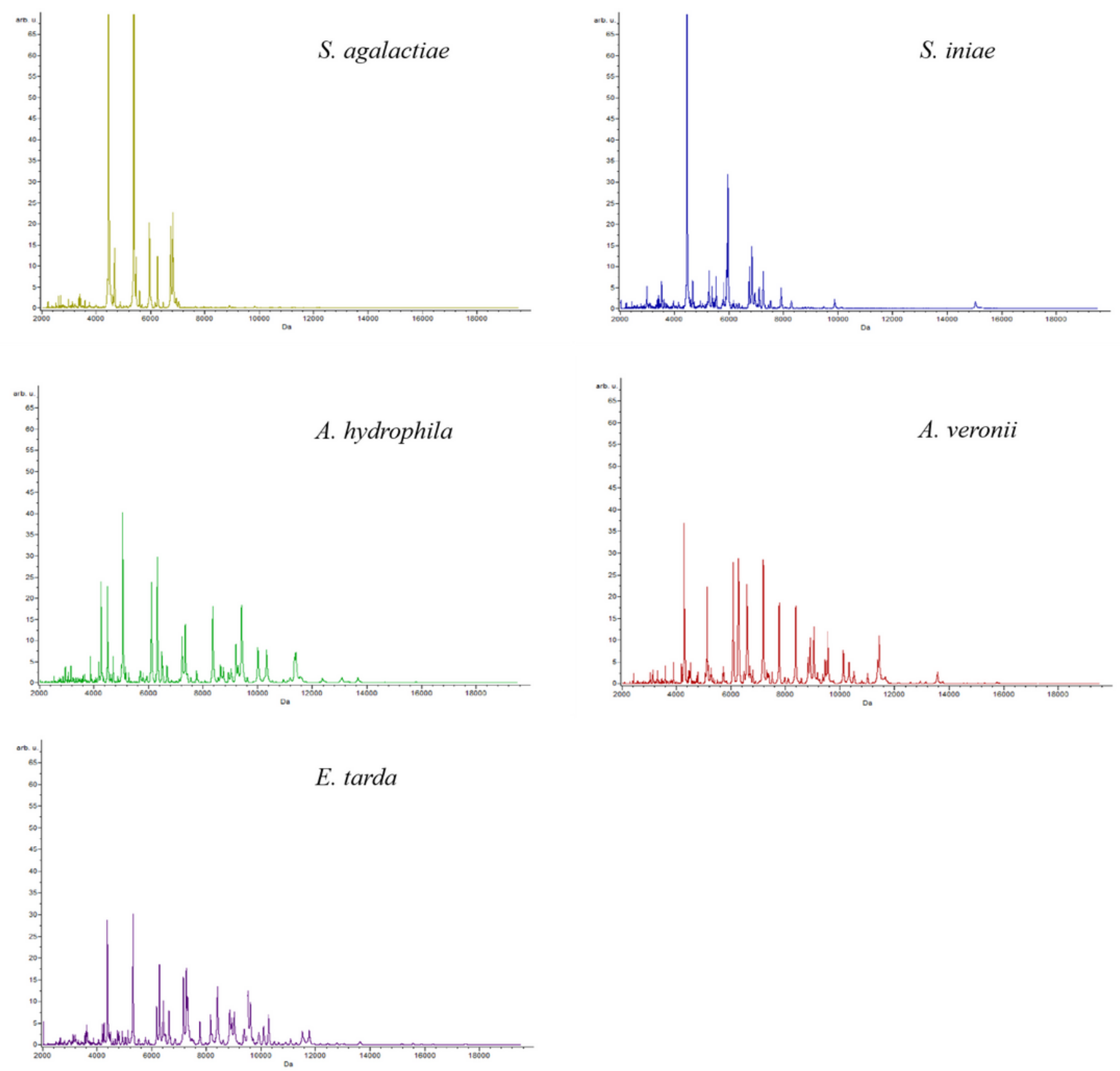

\section{Figure 1}

Mass peptide fingerprints of five bacterial pathogens (S. agalactiae, S. iniae, A. hydrophila, A. veronii and E. tarda) isolated from cultured fish. 

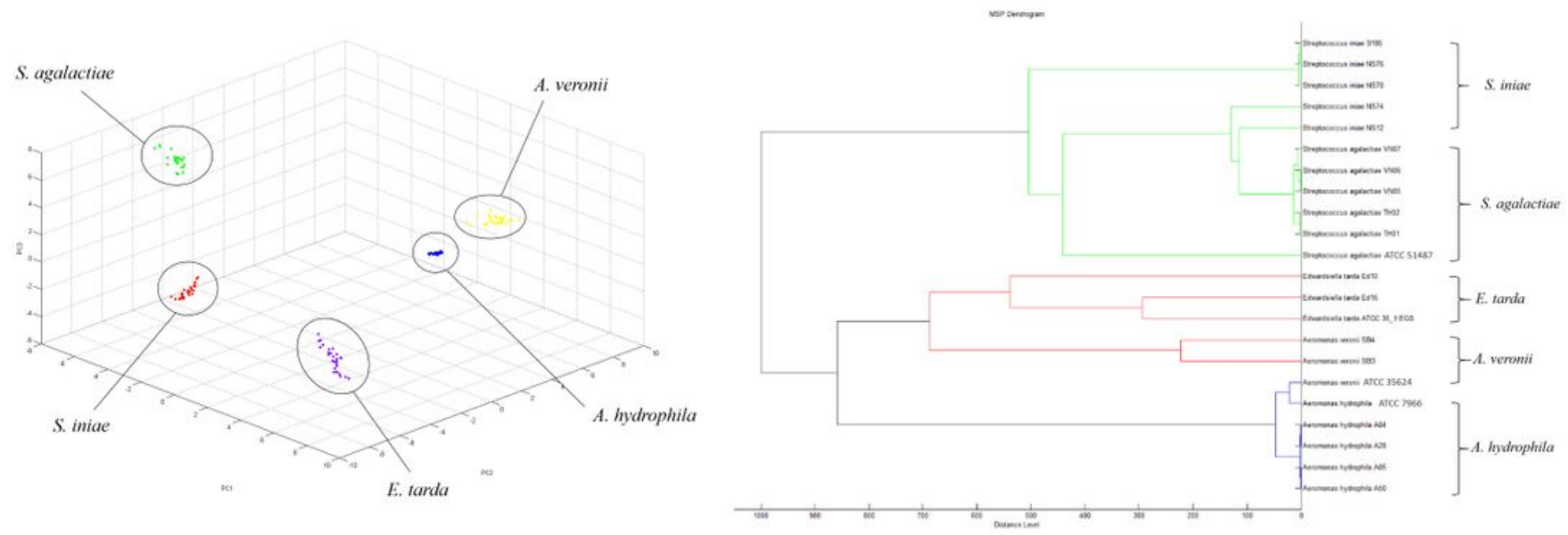

\section{Figure 2}

Cluster analysis of the five bacterial pathogens (S. agalactiae, S. iniae, A. hydrophila, A. veronii and E. tarda) isolated from cultured fish. (A) The 3D-PCA scatterplot representing clusters of each species (dashed circles) and the (B) MSP dendrogram of the representative bacterial isolates analyzed in the present study with the reference ATCC strains. 